\title{
Effect of Vitamin D Supplementation on Glucose Control and Inflammatory Response in Type II Diabetes: A Double Blind, Randomized Clinical Trial
}

\author{
Mohammed E. Al-Sofiani ${ }^{1,2,}$; Anwar Jammah ${ }^{2}$; Michael Racz ${ }^{1}$; Rajab A. Khawaja ${ }^{2}$; Rana \\ Hasanato $^{2}$; Hassan A. N. El-Fawal ${ }^{1}$; Shaker A. Mousa ${ }^{1,3}$; Darius L. Mason ${ }^{1}$ \\ ${ }_{1}^{1}$ Internal Medicine, Catholic Health System, University at Buffalo, Buffalo, New York, USA \\ ${ }^{2}$ College of Medicine, King Saud University, Riyadh, Saudi Arabia \\ 3 Pharmaceutical Research Institute, Rensselaer, New York, USA \\ ${ }^{*}$ Corresponding author: Mohammed E. Al-Sofiani, Internal Medicine, Catholic Health System, University at Buffalo, Buffalo, New York, USA. Tel: +1-5182539929, E-mail: mealsofi@ \\ buffalo.edu
}

Received: August 8, 2014; Revised: November 16, 2014; Accepted: November 24, 2014

\begin{abstract}
Background: Diabetes mellitus (DM) and vitamin D deficiency are major health concerns around the world. Evidence suggests a possible role of vitamin D in improvement of insulin secretion and sensitivity.

Objectives: We assessed whether vitamin D supplementation could be used in vitamin D deficient-type II diabetes to improve glucose metabolism, components of metabolic syndrome (MetS) and specific inflammatory biomarkers.

Patients and Methods: A double blind, randomized clinical trial was conducted in King Khalid University Hospital, Saudi Arabia to evaluate the effect of cholecalciferol supplementation on glycemic control, MetS components and specific inflammatory biomarkers including tumor necrosis factor-alpha (TNF- $\alpha$ ), Interleukin (IL-6), leptin, adiponectin and vascular cell adhesion molecule-1 (VCAM-1). Twenty-two patients with type II diabetes with insulin resistance, glycated hemoglobin (HbA1c) $\geq 6(42 \mathrm{mmol} / \mathrm{mol}$ ) and serum $25(\mathrm{OH}) \mathrm{D}<$ $50 \mathrm{nmol} / \mathrm{L}$ were randomized using a computer program to receive either supplementation with cholecalciferol (5000 IU/day) or placebo for 12 weeks. The primary outcome was change in HbAic levels from baseline.

Results: Median $[\mathrm{IQR}] 25(\mathrm{OH}) \mathrm{D}$ levels increased significantly in the vitamin D group as $58.1[48,67.3] \mathrm{nmol} / \mathrm{L}(\mathrm{P}=0.002)$. There was no significant difference in the change of HbAic between the groups $(\mathrm{P}=0.5)$ with a decrease of $-0.1 \%[-1,0.5]$ in the vitamin $\mathrm{D}$ group and an increase of $0.15 \%[0.1,0.2]$ in the placebo group. A significant improvement was observed in the homeostasis model of assessment of $\beta$-cell activity $(\mathrm{HOMA}-\% \mathrm{~B})(\mathrm{P}=0.03)$ with vitamin $\mathrm{D}$ supplementation compared to baseline.

Conclusions: Vitamin D repletion for 12 weeks increased serum vitamin D concentrations and improved $\beta$-cell activity in vitamin D-deficient type II diabetes with no significant changes in HbA1c or insulin sensitivity.
\end{abstract}

Keywords:Diabetes Mellitus; Insulin Resistance; Vitamin D

\section{Background}

Diabetes mellitus (DM) is a major health care challenge around the world. Saudi Arabia is among the world's tenth highest countries for DM prevalence (1). According to the International Diabetes Federation, $13.6 \%$ of the Saudi population between 20 and 79 years old have diabetes (1). Vitamin D deficiency is another major health concern associated with a number of extra-skeletal diseases including DM (2). Vitamin D responsive element (VDRE) has been identified in the promoter region of insulin receptor gene in human (3). Mice lacking vitamin D receptors (VDR) displayed an impairment of insulin secretion and sensitivity (4). The anti-inflammatory activity of vitamin D plays an important role in insulin secretion and sensitivity, since inflammation is considered a driving factor for insulin resistance (IR), metabolic syndrome (MetS), DM and their micro- and macro-vascular complications (5). Cytokines such as CRP, IL-6, IL-8, TNF- $\alpha$, and IL-18 and hyperglycemia are known as activators for expression of adhesion molecules, vascular cell adhesion molecules-1 (sVCAM-1), inter- cellular adhesion molecules-1 (sICAM-1), E-selectin and Pselectin $(6,7)$. Activation of the latter molecules is an early step in the formation of vascular atherosclerosis and their plasma levels can be used clinically as targets for therapy and predictors for complication in DM management (5). Cross-sectional studies in humans demonstrated a negative correlation between vitamin D and HbAic levels $(8,9)$. Daily consumption of vitamin D-fortified yogurt (containing vitamin D3 $1000 \mathrm{IU} /$ day and calcium (Ca) $300 \mathrm{mg} / 250$ $\mathrm{mL}$ ) or vitamin $\mathrm{D}+$ Ca-fortified yogurt (containing vitamin D3 $1000 \mathrm{IU} /$ day and Ca $500 \mathrm{mg} / 250 \mathrm{~mL}$ for 12 weeks significantly decreased HbAlc, homeostasis model assessment of insulin resistance (HOMA)-IR, waist circumference and BMI in comparison to a daily consumption of plain yogurt (containing no vitamin D3 and Ca $300 \mathrm{mg} / 250 \mathrm{~mL}$ ) (10). In a trial of ten women with diabetes, daily supplementation of 1332 IU cholecalciferol for one month increased the first phase insulin secretion significantly (11). On the other hand, a single dosage of oral cholecalciferol (100000 or

Copyright (C) 2015, Research Institute For Endocrine Sciences and Iran Endocrine Society. This is an open-access article distributed under the terms of the Creative Commons Attribution-NonCommercial 4.0 International License (http://creativecommons.org/licenses/by-nc/4.0/) which permits copy and redistribute the material just in noncommercial usages, provided the original work is properly cited. 
$200000 \mathrm{IU})$ for patients with type II diabetes showed no significant changes in blood glucose, insulin secretion or sensitivity (12).

\section{Objectives}

In the current pilot study, we hypothesized that vitamin D supplementation in vitamin D deficient-type 2 diabetes would have beneficial effects on glucose metabolism, components of MetS and inflammatory biomarkers including IL-6, TNF- $\alpha$, adiponectin and leptin.

\section{Patients and Methods}

This was a randomized, placebo-controlled, double-blind trial. Adults (aged 21 to 75 years) with type II diabetes and normal renal function, glycated hemoglobin (HbA1c) $\geq$ $6(42 \mathrm{mmol} / \mathrm{mol})$, hypovitaminosis D (serum 25(OH)D $<$ $20 \mathrm{ng} / \mathrm{mL}$ ) and insulin resistance (HOMA-IR $\geq 2$ ) were screened for the study in the primary care clinic at King Khalid University Hospital (KKUH), Riyadh, Saudi Arabia. The present study was approved by the Institutional Review Board at KKUH and registered at the Australian New Zealand Clinical Trial Registry (ACTRN12612000714886). A written, informed consent was obtained from all patients prior to their enrollment. Patients receiving stable oral hypoglycemic drug regimen for at least 30 days prior to screening were recruited. Subjects receiving lipid lowering drug or antihypertensive drug should have given a stable regimen for at least 30 days. Exclusion criteria were chronic liver disease, proteinuria (> $3.5 \mathrm{~g} / 24$ hours), autoimmune or inflammatory diseases, myocardial infarction within the last six months, congestive heart failure, cerebrovascular accident, gastrointestinal malabsorption disorders, hypercalcemia (serum $\mathrm{Ca}^{2+}>10.2 \mathrm{mg} / \mathrm{dL}$ ), primary parathyroid disorder or using active vitamin D analogs, nutritional vitamin D agents $>800 \mathrm{IU} /$ day, glucocorticoid, antiepileptics, carbamazepine, digoxin, cholestyramine or orlistat. Because exogenous insulin might affect the HOMA model, we excluded subjects who used insulin.

\subsection{Randomization and Masking}

Eligible patients $(n=22)$ were randomly assigned using a simple computer-generated program randomization list to either supplementation with cholecalciferol (5000 IU/day) or placebo for 12 weeks. The placebo was matched to the cholecalciferol capsules for shape, size and color (Bio-Tech-Pharmacal, Fayetteville, AR, USA). Patients and providers were blinded to treatment randomization. The study subjects were instructed not to change the type or dosage of any of their medications throughout the study.

\subsection{Procedures}

There were three study visits during the 12-week treatment phase. Fasting blood samples and anthropometric measurements were obtained at each visit. Waist circumference (WC) was measured at the midpoint level between the iliac crest and the lowest rib at the end of expiration. The samples were kept at $-80^{\circ} \mathrm{C}$ until the day of analysis. Serum $25(\mathrm{OH}) \mathrm{D}$ and $1,25(\mathrm{OH}) 2 \mathrm{D} 3$ were measured using the LIASON® chemiluminescent immunoassay (CLIA) and liquid chromatography-tandem mass spectrometry (LC-MS/MS), respectively. Insulin and parathyroid hormone (PTH) were measured using the Cobas ${ }^{\circledR}$ electrochemiluminescence immunoassay (ECLIA, USA), whereas parathyroid hormone-related peptide (PTHrP) (Biotang, Inc., cat\# HU9321), vascular cell adhesion molecule-1 (VCAM-1) (R\&D Systems, Inc., cat\# DVC00) and osteoprotegerin (OPG, R\&D Systems, Inc., cat\# DY805) were measured using enzyme-linked immunosorbent assay (ELISA) kits. Plasma concentrations of adiponectin, tumor necrosis factor-alpha (TNF- $\alpha$ ), interleukin (IL-6), and leptin (R\&D systems, Inc., catalog \# FCST08) were determined using a multiplex human obesity custom premix kit. The homeostasis model assessment (HOMA) was used to calculate insulin resistance (HOMA-IR) [FPI $\mathrm{x}$ FPG/22.5] and $\beta$-cell's function (HOMA-\%B) [20 × FPI) / (FPG - 3.5)], where FPI is fasting plasma insulin concentration $(\mathrm{mU} / \mathrm{L})$ and FPG is fasting plasma glucose $(\mathrm{mmol} / \mathrm{L})$.

\subsection{Statistical Analysis}

A sample of 14 patients (7 per group) was required to detect a significant change of $0.5 \%$ in HbA1c level after vitamin D supplementation with an $80 \%$ power and a twosided 5\% significance level. This was based on the assumption that the standard deviation of HbA1c is 0.3 according to a study performed on 92 Arabic patients with diabetes in Kuwait (13). To allow for dropouts, 22 patients were recruited and randomly assigned to vitamin $\mathrm{D}(\mathrm{n}=11)$ or placebo groups $(\mathrm{n}=11)$. Statistical analysis was performed using StatCrunch software. Normally distributed data were reported as means and standard deviations (SD), whereas non-normally distributed data were reported as median and interquartile range [IQR]. Non-parametric tests were used to compare the groups (Mann-Whitney $\mathrm{U}$ test) and to compare changes in measures within the groups (Wilcoxon-Signed Rank). A two-tailed P value of $<$ 0.05 was considered statistically significant.

\section{Results}

Of 22 patients, 20 completed the study (15 males and 5

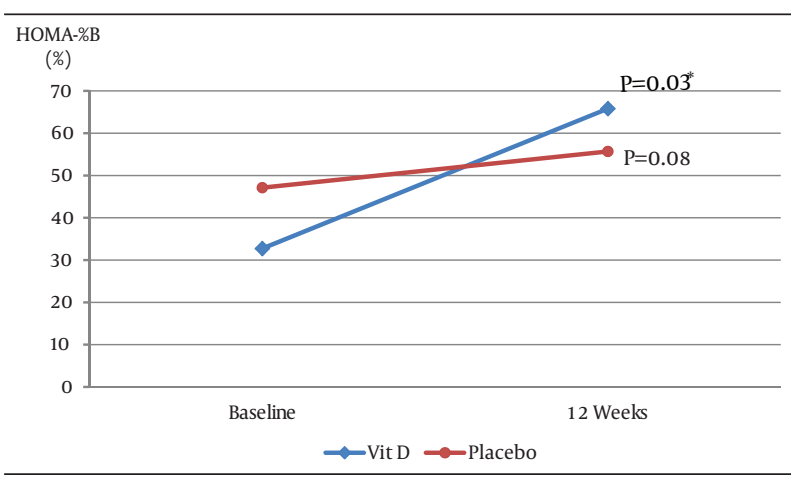

Figure 1. Changes in HOMA-\%B Medians From Baseline to Week 12 in the Two Groups 
Al-Sofiani ME et al.

Table 1. Changes From Baseline to Endpoint Measures of Outcomes Within Vitamin D and Placebo Groups and Between the Groups (Median Values and 25th, 75th Percentiles) $^{\mathrm{a}}$

\begin{tabular}{|c|c|c|c|c|c|c|c|}
\hline & \multicolumn{3}{|c|}{$\operatorname{Vitamin} D(n=10)$} & \multicolumn{3}{|c|}{$\operatorname{Placebo}(\mathbf{n}=10)$} & \multirow{2}{*}{$\begin{array}{l}\text { PValue(Difference } \\
\text { Between Groups) }\end{array}$} \\
\hline & Median & $\begin{array}{c}\text { 25th, 75th } \\
\text { Percentiles }\end{array}$ & $\begin{array}{c}\text { Pvalue (Difference } \\
\text { Within Group) }\end{array}$ & Median & $\begin{array}{c}\text { 25th, 75th } \\
\text { Percentiles }\end{array}$ & $\begin{array}{c}\text { P Value (Difference Within } \\
\text { Group) }\end{array}$ & \\
\hline \multicolumn{8}{|l|}{$25(\mathrm{OH}) \mathrm{D}, \mathrm{nmol} / \mathrm{L}$} \\
\hline Baseline & 25.35 & $22.3,28.9$ & & 38.65 & $23.7,39.7$ & & \\
\hline End & 91.1 & $74.6,99.3$ & & 29.4 & $23.1,34.2$ & & \\
\hline Change: End - Baseline & 58.05 & $48,67.3$ & 0.002 & -6.85 & $-12,0.6$ & 0.23 & $<0.0001$ \\
\hline \multicolumn{8}{|l|}{$1,25(\mathrm{OH})_{2} \mathrm{D} 3, \mathrm{nmol} / \mathrm{L}$} \\
\hline Baseline & 0.14 & $0.07,0.22$ & & 0.10 & $0.08,0.14$ & & \\
\hline End & 0.31 & $0.26,0.38$ & & 0.13 & $0.09,0.16$ & & \\
\hline Change: End-Baseline & 0.16 & $0.04,0.23$ & 0.002 & 0.002 & $-0.03,0.03$ & 0.85 & 0.0007 \\
\hline \multicolumn{8}{|l|}{ A1c, $\%$} \\
\hline Baseline & 7.95 & $6.9,9.4$ & & 6.9 & $6.4,7.3$ & & \\
\hline End & 7.85 & $6.6,9.8$ & & 6.95 & $6.7,7.5$ & & \\
\hline Change: End-Baseline & -0.1 & $(-1,0.5)$ & 1 & 0.15 & $0.1,0.2$ & 0.066 & 0.52 \\
\hline \multicolumn{8}{|l|}{ FBG, $\mathrm{mmol} / \mathrm{L}$} \\
\hline Baseline & 9.4 & $8.2,11$ & & 8.05 & $6.8,9.8$ & & \\
\hline End & 8.9 & $6.2,11$ & & 7.5 & $6.5,8.2$ & & \\
\hline Change: End-Baseline & -0.75 & $-3,0.8$ & 0.25 & -0.55 & $-1.3,-0.3$ & 0.0059 & 0.97 \\
\hline \multicolumn{8}{|l|}{ Insulin, $\mu \mathrm{U} / \mathbf{m L}$} \\
\hline Baseline & 8.11 & $6.94,10.47$ & & 10.94 & $6.95,12.83$ & & \\
\hline End & 10.56 & $8.34,15.58$ & & 11.68 & $7.54,15.9$ & & \\
\hline Change: End-Baseline & 1.82 & $-0.78,7.61$ & 0.11 & 1.16 & $-1.58,2.67$ & 0.375 & 0.44 \\
\hline \multicolumn{8}{|l|}{ HOMA-IR } \\
\hline Baseline & 3.17 & $2.56,5.41$ & & 3.82 & $2.48,4.94$ & & \\
\hline End & 4.13 & $2.3,6.83$ & & 3.72 & $2.76,4.87$ & & \\
\hline Change: End-Baseline & 0.35 & $-1.13,1.36$ & 0.77 & -0.07 & $-0.67,0.45$ & 0.7 & 0.63 \\
\hline \multicolumn{8}{|l|}{ НОМА-\%В, \% } \\
\hline Baseline & 32.73 & $24.87,43.72$ & & 47.12 & $30.15,80.19$ & & \\
\hline End & 65.82 & $34.54,86.08$ & & 55.68 & $31.23,112.04$ & & \\
\hline Change: End-Baseline & 35.9 & $(-3.11,42.67)$ & 0.03 & 7.3 & $(-2.73,20.84)$ & 0.08 & 0.48 \\
\hline \multicolumn{8}{|l|}{ SBP, mmHg } \\
\hline Baseline & 144.5 & 138,155 & & 137 & 122,144 & & \\
\hline End & 133 & 122,147 & & 139 & 124,150 & & \\
\hline Change: End-Baseline & -4.5 & $-23,7$ & 0.22 & 1 & $-2,2$ & 0.47 & 0.09 \\
\hline \multicolumn{8}{|l|}{ DBP, $\mathrm{mmHg}$} \\
\hline Baseline & 78.5 & 67,88 & & 74 & 69,83 & & \\
\hline End & 77 & 62,89 & & 74 & 66,80 & & \\
\hline Change: End - Baseline & -2.5 & $-7,5$ & 0.36 & -3 & $-5,1$ & 0.2 & 0.88 \\
\hline \multicolumn{8}{|l|}{ BMI, $\mathrm{Kg} / \mathrm{m}^{2}$} \\
\hline Baseline & 28.8 & $26.7,30.88$ & & 33.35 & $27.34,35.56$ & & \\
\hline End & 28.33 & $27.24,31.58$ & & 33.13 & $27.42,36.44$ & & \\
\hline Change: End - Baseline & 0 & $-0.35,0.55$ & 0.64 & 0.39 & $-0.69,0.68$ & 0.7 & 0.68 \\
\hline \multicolumn{8}{|l|}{ WC, $\mathbf{c m}$} \\
\hline Baseline & 109.5 & $103.5,113$ & & 114 & $105.5,124$ & & \\
\hline End & 108.25 & 101,112 & & 110.5 & 102,120 & & \\
\hline Change: End-Baseline & -1 & $-3,0.5$ & 0.33 & -2.75 & $-4,0$ & 0.14 & 0.24 \\
\hline Corrected $\mathrm{Ca}^{2+}, \mathrm{mmol} / \mathrm{L}$ & & & & & & & \\
\hline Baseline & 7.86 & $7.2,10.72$ & & 9.6 & $6.6,11.84$ & & \\
\hline End & 9.46 & $8.6,11.8$ & & 8.2 & $7.2,10.92$ & & \\
\hline Change: End - Baseline & 1.22 & $1,1.4$ & 0.004 & 0.08 & $(-2.28,1.08)$ & 0.77 & 0.06 \\
\hline Albumin, $g / L$ & & & & & & & \\
\hline Baseline & 42 & 38,43 & & 39.5 & 36,43 & & \\
\hline End & 40 & 38,41 & & 41 & 38,42 & & \\
\hline Change: End-Baseline & -1.5 & $-2,-1$ & 0.013 & -0.5 & $-2,2$ & 0.95 & 0.16 \\
\hline Alkaline Phosphatase, $\mathrm{U}$ & & & & & & & \\
\hline Baseline & 114.5 & 105,136 & & 86.5 & 74,106 & & \\
\hline End & 111.5 & 100,126 & & 88.5 & 76,113 & & \\
\hline Change: End - Baseline & -4.5 & $-10,2$ & 0.097 & -4 & $-7,10$ & 0.8 & 0.47 \\
\hline TNF- $\alpha, p g / m L$ & & & & & & & \\
\hline Baseline & 53.87 & $51.46,62.27$ & & 59.28 & $55.07,70.63$ & & \\
\hline End & 51.46 & $47.83,57.48$ & & 52.66 & $47.83,59.88$ & & \\
\hline Change: End - Baseline & -0.6 & $-8.46,4.82$ & 0.74 & -6.6 & $-17,-2.42$ & 0.01 & 0.08 \\
\hline
\end{tabular}


females). Two patients left the study due to moving overseas $(n=1)$ or personal reasons $(n=1)$. The mean \pm SD ages (Vitamin D group: $54.8 \pm 9.16$ years; placebo group: $55 \pm$ 11.99 years) and duration of diabetes (Vitamin D group: 9.3 \pm 5.62 years; and placebo group: $7.4 \pm 5.08$ years) were not significantly different between the two groups. Compliance to study medications, assessed by counting unused capsules in each visit, was approximately $97 \%$ in the two groups. At baseline, there was a significant positive correlation between HOMA-IR and BMI $(\mathrm{r}=0.4653, \mathrm{P}=0.04)$ and an inverse correlation between HOMA-IR and adiponectin $(\mathrm{r}=-0.4543, \mathrm{P}=0.04)$ in the two groups. Table 1 shows baseline values and changes after 12 weeks in the two groups. Serum 25(OH)D increased significantly in the vitamin D group as $58.1[48,67.3] \mathrm{nmol} / \mathrm{L}$ at week $12(\mathrm{P}=0.002)$. The vitamin $\mathrm{D}$ group was associated with a significant increase in $1,25(\mathrm{OH}) 2 \mathrm{D} 3$ as $0.16[0.04,0.23] \mathrm{nmol} / \mathrm{L}(\mathrm{P}=0.002)$ and a significant increase in $\mathrm{Ca}^{2+}(\mathrm{P}=0.004)$ as $1.22[1.0,1.4]$ $\mathrm{mmol} / \mathrm{L}$. There was no significant difference in the change of HbA1c between the groups $(\mathrm{P}=0.52)$, with a decrease of $-0.1 \%[-1,0.5]$ in the vitamin $\mathrm{D}$ group and an increase of $0.15 \%$ $[0.1,0.2]$ in the placebo group. In the vitamin $\mathrm{D}$ group, HOMA-\%B increased significantly by $35.9 \%[-3.11,42.67]$ ( $\mathrm{P}=$ 0.03 ) (Figure 1) and insulin increased by $1.82[-0.78,7.61] \mu \mathrm{U} /$ $\mathrm{mL}(\mathrm{P}=0.11)$ compared with baseline. Changes in HOMA-IR, BMI, WC, diastolic BP (DBP) and unpublished lipid profile (HDL, LDL, TG, and cholesterol) were not significant within, and did not differ, between the groups. Systolic blood pressure (SBP) decreased by $-4.5[-23,7] \mathrm{mmHg}(\mathrm{P}=0.22)$ in the vitamin $\mathrm{D}$ group and increased by $1[-2,2] \mathrm{mmHg}(\mathrm{P}=$ $0.47)$ in the placebo group. The difference in the change of SBP between the groups was not statistically significant ( $P$ $=0.09)$. A significant reduction of $-6.6[-17,-2.42] \mathrm{pg} / \mathrm{mL}(\mathrm{P}$ $=0.01$ ) in TNF- $\alpha$ was found in the placebo group. However, there was no significant difference in the changes of TNF- $\alpha$ between the groups $(\mathrm{P}=0.08)$. Changes in OPG, VCAM-1, adiponectin, IL-6 and leptin were not significant within, and did not differ between the groups (data not shown).

\section{Discussion}

We found that supplementation with 5000 IU/day cholecalciferol for 12 weeks effectively increased the $25(\mathrm{OH})$ D from deficient to sufficient levels (i.e. from $<50$ to $>$ $75 \mathrm{nmol} / \mathrm{L}$ as defined by the Institute of Medicine) (14). Moreover, increase in 25(OH)D increased the concentration of $1,25(\mathrm{OH})_{2} \mathrm{D}_{3}$ significantly. The correction of $25(\mathrm{OH})$ D deficiency in our study was associated with a significant improvement in $\beta$-cell activity (HOMA-\%B), but not HbA1c levels or insulin resistance. The HOMA-\%B model has been used clinically and in diabetic research as a simple tool to assess the effect of treatment since the improvement in HOMA-\%B reflects an improvement in the ability of pancreatic beta cells to produce insulin. Improvement in $\beta$-cell function after vitamin $D$ repletion could be explained by both genomic and nongenomic actions of vitamin D. Insulin producing $\beta$-cells express both nuclear and membranous receptors for $1,25(\mathrm{OH})_{2} \mathrm{D}_{3}$. The nuclear receptors modulate the genomic insulinotropic actions of vitamin $\mathrm{D}$, whereas the membrane receptors enhance the $\mathrm{Ca}^{2+}$ influx in $\beta$-cells, an essential step for glucose-induced insulin secretion (15). Vitamin D mediates the $\mathrm{Ca}^{2+}$ dependent endopeptidase activities to convert pro-insulin to insulin. Interestingly, $\beta$-cells have the ability to hydroxylate $25(\mathrm{OH}) \mathrm{D}$ to the active form $1,25(\mathrm{OH})_{2} \mathrm{D}_{3}$ through its own $1-\alpha$ hydroxylase enzyme (16). Improvement in $\beta$-cell activity in our study was associated with a non-statistically significant increase in serum insulin levels. Similar improvement in HOMA-\%B and insulin secretion was noted in another study of Arab participants after daily supplementation with 2000 IU cholecalciferol for 12 months (17). Despite lower levels of BP, HbA1c, FBG and lipid profile in the placebo group at baseline compared to the vitamin $\mathrm{D}$ group, which may indicate a possible better health status of the former group, we showed a median reduction of $4.5 \mathrm{mmHg}$ in the SBP after 12 weeks of vitamin D supplementation. Although the difference in the changes of SBP between vitamin $\mathrm{D}$ and placebo groups was not statistically significant $(P=0.09)$, reduction may be of clinical significance. Antihypertensive activity of vitamin D could be related to negative regulatory effect of vitamin $\mathrm{D}$ on renin production (18). General healthier status of the placebo group as abovementioned could explain the positive response in both FBG and TNF- $\alpha$ in this group. Moreover, we did not control time of day that blood was collected or prior exercise status for our study subjects, both of which are factors shown to influence FBG levels (19). The absence of correlation between changes in TNF- $\alpha$ levels and HOMA$\% \mathrm{~B}$ in the two groups is a thought-provoking finding. This may indicate that beneficial effect of vitamin $\mathrm{D}$ on beta cell function is independent from anti-inflammatory activities of vitamin $\mathrm{D}$ and such speculation needs to be studied further. Limitations of our study were the small sample size and short duration of vitamin D supplementation, which might be insufficient to show significant changes in insulin sensitivity and HbA1c. Von Hurst et al. showed no improvements in insulin sensitivity until six months of cholecalciferol supplementation (20). However, three to four weeks of vitamin D supplementation was sufficient to improve insulin secretion in other studies $(11,21)$. The strengths of the present study were its prospective, double-blind, and randomized design with a placebo group, inclusion of only vitamin D deficient type II diabetes with insulin resistance, achieving optimal vitamin D status in the vitamin D group at the end of study, stable treatment regimen throughout the study and objective assessment of endpoints and compliance to medication. Vitamin D deficiency is highly prevalent in Saudi population including those with diabetes (22). Vitamin D supplementation may positively influence $\beta$-cell function in patients with type II diabetes who are vitamin D-deficient. Future studies examining the benefits of vitamin D correction in type II diabetes are warranted to confirm the true metabolic effects of vitamin D supplementation. 


\section{Acknowledgements}

We would like to acknowledge the academic and financial support of King Saud University and the Pharmaceutical Research Institute, Rensselaer, NY. Besides, we are so grateful to the study subjects for their cooperation and compliance.

\section{Funding/Support}

The Pharmaceutical Research Institute, Rensselaer, NY USA King Saud University, Riyadh, Saudi Arabia supported this study financially.

\section{References}

1. International Diabetes Federation.. 2013. Available from: http:/| www.idf.org/membership/mena/saudi-arabia\#membership.

2. Holick MF. Vitamin D deficiency. N Engl J Med. 2007;357(3):266-81.

3. Maestro B, Davila N, Carranza MC, Calle C. Identification of a Vitamin $D$ response element in the human insulin receptor gene promoter. J Steroid Biochem Mol Biol. 2003;84(2-3):223-30.

4. Zeitz U, Weber K, Soegiarto DW, Wolf E, Balling R, Erben RG. Impaired insulin secretory capacity in mice lacking a functional vitamin D receptor. FASEB J. 2003;17(3):509-11.

5. Garcia C, Feve B, Ferre P, Halimi S, Baizri H, Bordier L, et al. Diabetes and inflammation: fundamental aspects and clinical implications. Diabetes Metab. 2010;36(5):327-38.

6. Goldberg RB. Cytokine and cytokine-like inflammation markers, endothelial dysfunction, and imbalanced coagulation in development of diabetes and its complications.J Clin Endocrinol Metab.2009;94(9):3171-82.

7. Quagliaro L, Piconi L, Assaloni R, Da Ros R, Maier A, Zuodar G, et al. Intermittent high glucose enhances ICAM-1, VCAM-1 and Eselectin expression in human umbilical vein endothelial cells in culture: the distinct role of protein kinase $C$ and mitochondrial superoxide production. Atherosclerosis. 2005;183(2):259-67.

8. Kositsawat J, Freeman VL, Gerber BS, Geraci S. Association of A1C levels with vitamin D status in U.S. adults: data from the National Health and Nutrition Examination Survey. Diabetes Care. 2010;33(6):1236-8.

9. Hypponen E, Power C. Vitamin D status and glucose homeostasis in the 1958 British birth cohort: the role of obesity. Diabetes Care. 2006;29(10):2244-6.
10. Nikooyeh B, Neyestani TR, Farvid M, Alavi-Majd H, Houshiarrad A, Kalayi A, et al. Daily consumption of vitamin D- or vitamin D + calcium-fortified yogurt drink improved glycemic control in patients with type 2 diabetes: a randomized clinical trial. Am J Clin Nutr. 2011;93(4):764-71.

11. Borissova AM, Tankova T, Kirilov G, Dakovska L, Kovacheva R. The effect of vitamin D3 on insulin secretion and peripheral insulin sensitivity in type 2 diabetic patients. Int J Clin Pract. 2003;57(4):258-61.

12. Witham MD, Dove FJ, Dryburgh M, Sugden JA, Morris AD, Struthers AD. The effect of different doses of vitamin $\mathrm{D}(3)$ on markers of vascular health in patients with type 2 diabetes: a randomised controlled trial. Diabetologia. 2010;53(10):2112-9.

13. Al-Shoumer KA, Al-Asousi AA, Doi SA, Vasanthy BA. Serum leptin and its relationship with metabolic variables in Arabs with type 2 diabetes mellitus. Ann Saudi Med. 2008;28(5):367-70.

14. Institute of Medicine.. Dietary Reference Intakes for Calcium and Vitamin D.Washington, DC: The National Academies Press; 2011.

15. Kajikawa M, Ishida H, Fujimoto S, Mukai E, Nishimura M, Fujita J, et al. An insulinotropic effect of vitamin D analog with increasing intracellular Ca2+ concentration in pancreatic betacells through nongenomic signal transduction. Endocrinology. 1999;140(10):4706-12.

16. Bland R, Markovic D, Hills CE, Hughes SV, Chan SL, Squires PE, et al. Expression of 25-hydroxyvitamin D3-1alpha-hydroxylase in pancreatic islets. J Steroid Biochem Mol Biol. 2004;89-90(1-5):121-5.

17. Al-Daghri NM, Alkharfy KM, Al-Othman A, El-Kholie E, Moharram $\mathrm{O}$, Alokail MS, et al. Vitamin D supplementation as an adjuvant therapy for patients with T2DM: an 18-month prospective interventional study. Cardiovasc Diabetol. 2012;11:85.

18. Vaidya A, Williams JS. The relationship between vitamin $\mathrm{D}$ and the renin-angiotensin system in the pathophysiology of hypertension, kidney disease, and diabetes. Metabolism. 2012;61(4):450-8.

19. Moebus S, Gores L, Losch C, Jockel KH. Impact of time since last caloric intake on blood glucose levels. Eur J Epidemiol. 2011;26(9):719-28.

20. von Hurst PR, Stonehouse W, Coad J. Vitamin D supplementation reduces insulin resistance in South Asian women living in New Zealand who are insulin resistant and vitamin D deficient - a randomised, placebo-controlled trial. Br J Nutr. 2010;103(4):549-55.

21. Inomata S, Kadowaki S, Yamatani T, Fukase M, Fujita T. Effect of 1 alpha (OH)-vitamin D3 on insulin secretion in diabetes mellitus. Bone Miner. 1986;1(3):187-92.

22. Al-Daghri NM, Al-Attas OS, Al-Okail MS, Alkharfy KM, Al-Yousef MA, Nadhrah HM, et al. Severe hypovitaminosis D is widespread and more common in non-diabetics than diabetics in Saudi adults. Saudi Med J. 2010;31(7):775-80. 